\title{
The Married Migrant Women's Adaptation to Korean Society
}

\author{
Eun Mee Choi1)
}

\begin{abstract}
The study aims to learn about the difficulties multi-culture families experience from settling in Korea. Interviewing immigrant women reveal that the following three hardships are most commonly experienced. First of all, domestic trouble (marital/in-laws discord) became a serious issue. Secondly, a huge concern about education was detected as multi-culture children are more easily exposed to bullying at school which often causes their maladaptive behavior. Lastly, the lack of psychological/emotional support was a problem as both immigrant women and their children are dealing with racial discrimination in daily life. Immigrant women suffered from frustration over life in Korea disappointed with expectations. Thereafter, they continue to suffer due to prejudice and discrimination against the multicultural families. Thereafter, they received the familial support and the social and emotional support as well as the parental counseling so that they regained their confidence and came to adapt to Korean society through their independent effort to stand alone.
\end{abstract}

Keywords : The multicultural family, Migration to Korea, The married Migrant women, Maladaptation, Social support

\section{Introduction}

1. 1 The necessity of the research and purpose

Since 1990, the multicultural family composed of Korea's farm old bachelor and foreign female marriage began to establish. The multicultural family, defined in Article 2 of multicultural families support act, means the family that is composed of Korea's citizenship obtainer including married immigrants and the person who got the nationality by marriage[1]. Since then, the multicultural international marriage have increased to a great extent, and a lot of problems began to derive socially due to it. Among them, a random bunch of international matchmaking agencies have consummated multicultural marriage compulsorily, there were many cases for Korean spouse to face difficulties in each other due to wrong information,

Received(March 27, 2018), Review Result(1st: April 2, 2018, 2nd: April 27, 2018), Accepted(May 4, 2018)

${ }^{1}$ Dept. of Early Childhood Education, Baekseok Univ., 76 Munam-ro, Dongnam-gu, Cheonan-si, Chungcheongnam-do, Korea

email: emchoi@bu.ac.kr

* This Study was supported by research fund from Baekseok University, 2018 
and as unfortunate cases occurred it also caused a lot of controversy socially. The married migrant women that have migrated to a new country looses the personal relationships formed from her own country, and is places in maladaptation status such as anxiety, depression, feeling o $\mathrm{f}$ alienation, loss of identity as this kind of sudden change induces excessive stress[2-4].

When seeing the wedding trend of Korean and foreigner that has been accumulated by the National Statistical Office, and with the start of 6,545 cases in 1993 and in 2015, 42,356 cases of marriage, which was the most among the history was done. Until 2010, the multicultural marriage that was over 35,000 cases began to reduce beginning with the policy of 'International marriage soundness, that designates the law related to marriage broker company management and enforces the regulations to stop the indiscriminate international marriages by the government in 2010. As a result, with 35,098 cases of international marriage in 2010, it has reduced continuously after it reached the summit. Multicultural marriage in 2016 was 21,709 cases, which was reduced by $3.4 \%$ compared to last year, divorce was 10,631 cases reduced by $5.8 \%$, and the birth was 19,431 people which was reduced by $1.5 \%$ [5]. Divorce and birth rate is reducing as the multicultural marriage itself is reducing, but among the overall divorce, still the rate of multicultural family's divorce takes approximately $10 \%$, which is not a small rate at all. Compared to 15.4 years of Korean divorced couple, the average married life period, the multicultral family divorce was only 7.4 years, which we could know that the married life was more unstable than Korean couple. This figure, however, when recalling the fact that 2008 multicultral divorce family's married life period was only 3.7 years, as it is the period that is longer for more than 2 times, we could know that how much multicultural family's divorce problem was severe before. However, $36.7 \%$ among the multicultral divorce family was shown as the family that divorces within 5 years[5]. The problem of multicultural family gives negative effect on the child growth of multicultral family[6]. Not only the child's growth and educational problem occurred due to breakage of multicultral family, the interest and support is in urgent status for social maladaptation problem. In particular, the expansion of self-help center that helps independence socially by growing work ability and to protect the broken multicultral family composition is in needed status[7]. For the multicultral family to adapt to a new culture, they experience mental and physical stress[8], and when this is not overcome, they face difficulty physically, or may appear confusion of identity, depression, anxiety, feeling of helplessness due to psychological symptoms[9]. The Multicultural Family Support Act (2008) was established for social support such as multicultural family's livelihood or educational support[1], but we are in the necessity time to approach more deeply for psychological \& 
emotional support with these policy consideration. Recently, the autonomous region of Seoul city is executing programs to stabilize women in a multicultural family to adapt to the Korean society faster, and especially, it is currently operating 'Vento' which is the 'the multicultural family before and after birth caring service'. 'Vento', promoted by Seoul city and Hanlim University Gangnam Seongshim Hospital from last 2015, is helpful to the marriage of immigrant women who are about to give birth[10]. The immigrant women that is a full time house wife, who lives with a husband who works in the farm, tend to solve difficulties on her own, instead of seeking for advice actively or getting others help, or lives it without solving the problem[6][11]. There is a need to develop customized service for multicultural family through self-investigation by each regions. The multicultural family problem is mainly composed of the statistics investigated by the survey, and there aren't many cases of approaching to qualitative research compared to it. The purpose of this study is to interview the married migrant women's vivid experience, who is spending married life in Korea due to marriage and migration, and raising a child, and to find out specifically how they are adopting to Korean society by seeing what kinds of difficulties they are facing and what procedures they go through. This can be used as basic data for the multicultural family policy.

\subsection{Research problem}

The research problem according to above purpose are as follows.

First, what are the difficulties of the multicultural family's life in Korea?

Second, how does multicultural family adapt to Korean society?

\section{Research method}

\subsection{Investigation subject and data collection method}

The subject of this study is two Chinese women that have migrated to Korea due to marriage. Both of these women are ethnic Korean who graduated in a university in China, and is fluent in Korean. A, the migrant women, is 38 years old and migrated to Korea due to marriage by meeting a Korean by the introduction of a relative, that was working in department store in China. The length of stay in Korea is 10 years, and has 4 years age gap with the spouse. They have divorced after giving birth to one child, and after that, she has 
remarried, gave birth to one child, she now has two children, succeeded in getting a job, and she now works as a cashier. Migrant women B is 34 years old, came to Korea after marriage in China through a marriage broker company, the age gap with spouse is 12 years, and has 2 children. The period of staying in Korea is 8 years, and is a full time housewife. The inquiry area of interview is 3 largely, and have firstly searched for the reason of migrating to Korea, then searched for the socio-demographic background, then the difficulties of married life that began after migration to Korea, and was progressed in the form of the interviewee speaking freely about the adaptation to Korean society.

\subsection{Data analysis}

Under the consent of the interviewee, all contents were recorded, and by reading repeatedly, the important and meaningful contents were categorized. As the result of coding, 113 meaningful categories were made, and according to the similarity of the content, it was broadly grouped in to lower categories of 55 , higher categories of 23 , and this was again classified into 5 subjects.

\section{Research result}

Analysis result is provided according to the research problem. First, it was revealed that the biggest difficulty in adapting to a Korean society is their domestic problems, the problems regarding their children, their psychological problems, and their emotional problems. To begin with, the domestic problems include their distrust of the spouses, their discord with their mother-in-laws, their economic power, their divorce, and their remarriage. The biggest of the above-mentioned problems was a married immigrant woman's disappointing marriage with her spouse whose spouse's lies were revealed after the wedding so that the trust was lost, while she got to take the burden of not only rearing the children but also supporting the whole family (A). It was also revealed that even if the other married immigrant woman's relationship with the spouse was fortunately good, she was not accepted as a genuine family member in the husband's family so as to be psychologically hurt (B). When the husband's family denied the married immigrant woman the familial support which she had already once lost leaving her home country, her self-esteem got lowered as it could so that her life in Korea got anxious, and shrank. The poor economic power of the multicultural family made it difficult to 
treat the child early medically, and the divorce from which ensued dismantling of the family resulted in the difficult-to-overcome psychological trauma of the male child who was in the period of oedipus complex[12]. The divorce did not just simply ended the marriage as she did not acquire the waiver of paternity affidavit from her ex-husband so that she had to take legal action with the situation lingering on unsolved. When she remarried another man, it took her more than 2 years to adapt to him being the eldest son of the family, and to adapt to his family. Further, Korean males' patriarchal attitude is one of the factors to make the married immigrant women's marriage difficult. The difficulties of parenting the children resulted in educational underachieving, poor play environment, and the problem in getting the early medical treatment of the child. Help was needed for the educational underachieving which was caused by the child's speech disorder and intellectual disability. The parents who lacked time for play with the child was aware of the poor play environment in which there were not enough playthings. Especially in a case the married immigrant woman was employed, she had difficulty in supporting the child emotionally due to insufficient time and physical fatigue after work. Regarding the problem in getting the early medical treatment of the child, the parents reacted sensitively to the spouse's support or the teacher's recommendation while trying to actively intervene in the child's issue. However, they were in the economic situation where paid medical treatment couldn't be done before the pertinent voucher was issued to them. In the case of (A), she single-handedly supported a child who has intellectual challenges due to the child's brain injury caused by the forceps delivery, and at the same time she had to support the whole family. In this connection, the economic situation made it difficult to begin the paid early medical treatment of the child before the child had been diagnosed as disabled. Therefore, the parents on their own felt frustrated and angered with the situation, and strongly requested the doctor to diagnose the child as disabled who is on the border of disability, and therefore, the child could be pronounced as disabled. Whereupon, the married immigrant woman A felt a self-reproaching emotion that she made her child pronounced as disabled in order to get the child treated through the required voucher, while also feeling a sense of shame in spite of the acquired opportunity to treat the child medically. The child's intellectual disability not only simply made the child's learning difficult but also was accompanied by the child's emotional anxiety and problematic method of anger expression. In the case of B, the elder child had a speech disorder with pronunciation being unclear, and did not get along with the child's younger brother so as to have little opportunity to talk to him. In this vicious cycle, the parents also had difficulty in the parenting while being psychologically anxious without getting any help from the surroundings. Regarding the psychological and social 
problem, it was revealed that the prejudice overflowing in Korean society against the multicultural families made not only the married immigrant woman but also her children experience exclusion and discrimination, so that they are left emotionally anxious and psychologically shrunken. She feared building relationship with Koreans due to the prejudice. Furthermore, she was psychologically shrunken while she performs parenting of the special child beyond the range of the usual parenting, with the familial support lost. On the other hand, the child was also emotionally shrunken and depressed due to being excluded from the age group. Therefore, as the child could not resolve the stress appropriately, the child showed impulsive and aggressive aspect. In the case of B, she confined herself at homes avoiding going out for several years because of Koreans' prejudice, and therefore, she lead a life with a very limited number of people to communicate with. Consequently, she suffered from severe emotional shrinkage and psychological anxiety. The child of the married immigrant woman A did not adapt to the school life well because the child got excluded and made fun of due to the fact that the child adopted the mother's surname after the divorce. Especially, the child of the married immigrant woman A suffered emotionally very much from the home environment fraught with anxiety, and finally the divorce made the child experience the level of anxiety and depression which a young child could not handle (Refer to Table 1). It was revealed that the helpful countermeasure resources for the married immigrant woman to overcome the difficulties are the familial support, the social support, and the parental counseling. The familial support can be obtained from the woman's parents in the home country, brothers and sisters, her spouse, her husband's family, the relatives, etc. The social support can be gained by multicultural organizations, educational institutions, teachers, therapists, local communities, Korean neighbors, etc. Among the resources, what was helpful for their parenting role was the parent counseling, which they hoped would be increased. The parenting counseling is a very useful countermeasure resource to help prevent the transition of the fatigued parents' psychology to the child and also to help prevent wrong parenting behaviors in advance. However, the programs prepared in the Multicultural Centers focused on the married immigrant women from countries such as Philippines or Vietnam, and does not have any programs for Korean Chinese who can speak Korean. Therefore, the Korean Chinese do not get any help therefrom. Developing and enhancing various kinds of countermeasure resources can be a good way to help the married immigrant women grow the necessary ability to overcome the difficulties (Refer to Table 2).

Second, the adaptation to Korean society can be summarized approximately as 5 procedures. The first stage is when she experiences frustration due to the crumbled expectation at the 
beginning of the marriage. The interviewee A had her trust of her husband crumbled in the beginning of the marriage as soon as she came to Korea and found that her husband was without the job and the house which he talked about before the wedding. Even though she tried to lead a positive life together with him with the spirit that two heads are better than one, her husband was given to drinking and did not support the family. Therefore, she was placed in a plight that she alone had to rear the child and support the family. The interviewee B's only communication channel was her husband, and lived a lonely life in a village where you have to walk for 30 minutes to ride a bus. Furthermore, her husband's family did not like her going out, and therefore, she led an isolated life mostly remaining in the home. The second stage is when the woman suffers from difficulties due to prejudice. These difficulties due to prejudice existed not only externally but also in the home. The prejudice from the family caused the absence of the familial support. Both of the interviewees A and B were psychologically shrunken as they were not accepted genuinely as a family member from their husbands' families. In the case of the interviewee A, she did not have anyone to discuss the domestic affairs with because her husband and her mother-in-law drank heavily. In the case of the interviewee B, she was not acknowledged or supported by her husband's family because they regarded the young in-law who has a big age gap with her older husband as someone who may run away at any time. Such suspicion functioned as a factor that prevented her from being a established family member. Another kind of prejudice was the social prejudice, which caused lack of the social support. The interviewee A faced prejudice and discrimination from the Child Care Center due to the fact that they were basic livelihood security recipients, and her child also experienced exclusion from the child's age group due to the fact. In the case of the interviewee $\mathrm{B}$, her accent immediately revealed that she was an immigrant woman and therefore, she avoided contact with people confining herself to home while fearing people's discriminating looks. Both of the married immigrant women could not be integrated into the homes nor into the society while feeling rejected from the Korean people. The third stage is when they get the domestic and social backing and support. In the case of A, even though her child was on the border of disability, she lamentably could not afford to get her child the paid medical treatment. However, the voucher for the paid medical treatment was issued after her child was diagnosed as disabled so that she got hopeful that her child's symptom can be improved because the child can get the professional therapy for the educational underachieving as well as the psychological therapy simultaneously. In the case of the interviewee $B$, her child was receiving a speech therapy and an art therapy, and she was advised that the therapy for the child's speech disorder can be negatively affected by the child's emotional anxiety due to 
the parent's attitude as though they showed favoritism to the child's younger brother. Consequently, she reflected on herself in the procedure in which she tried to perform the parent's role well so that the parent and the child both got helped. In both cases of the interviewees A and B, they discussed with the therapists the children's problems which it had been difficult for them to solve alone, and they got advised about the problems. In this procedure, they came to open their heart and acquired the social support. After the treatment session of the child, parental counseling was provided in which the therapists and the parents were together so that the parents could learn how to do the roles of parents well. The fourth stage is when the woman stands alone independently. In the case of the interviewee A, she divorced the man who disregarded his responsibility and role as a patriarch. In this stage, she actively developed her own life to the extent that she offered to pay her spouse's debt on the condition that they would be divorced. In the case of interviewee B, she abandoned her previous attitude of avoiding other peoples' eyes, and instead she now openly makes clear that she is a married immigrant woman, and both she and her child came to rear their confidence as the child got treated for the emotional anxiety. In the final stage of adaptation, the interviewee A remarried another man to build a new home after the divorce, and gave birth to a second child, and got a stable job to lead a peaceful home life. In the case of the interviewee B, the above-mentioned anxiety of the husband's family developed into a situation that the woman's family in the home country was moved to Korea. As her family in the home country has moved to Korea, her once-lost familial support was reclaimed while she was also helped by her home-country parents in rearing the children. Consequently, she is now leading an emotionally stable life. As it approximately took 7-8 years for both of the women to adapt to the Korean society, we can see that we need not only the policies to help the married immigrant women to adapt to Korean society well in the beginning but also social consideration and care.

[Table 1] Difficult Problems in Adaptation to Korea

\begin{tabular}{|c|c|c|c|}
\hline & Problems & Matters & Detailed matters \\
\hline \multirow{3}{*}{$\begin{array}{l}\text { Difficul- } \\
\text { ties and } \\
\text { problems }\end{array}$} & \multirow{3}{*}{$\begin{array}{l}\text { Domestic } \\
\text { problems }\end{array}$} & Trust of spouses & $\begin{array}{l}\text { Lies, Irresponsibility, Drinking, Not knowing the } \\
\text { preciousness of their children }\end{array}$ \\
\hline & & $\begin{array}{l}\text { Discord between the } \\
\text { daughter-in-law and the } \\
\text { mother-in-law }\end{array}$ & $\begin{array}{l}\text { Feeling ashamed of the daughter-in-aw, Drinking, } \\
\text { Suspicion that the daughter-in-law would run } \\
\text { away, Excessive expectation of the pregnancy. }\end{array}$ \\
\hline & & Economic power & $\begin{array}{l}\text { Not being able to afford to get the necessary } \\
\text { early medical treatment due to the burden of the } \\
\text { medical fee, Being a basic livelihood security }\end{array}$ \\
\hline
\end{tabular}




\begin{tabular}{|c|c|c|c|}
\hline & & & recipient \\
\hline & \multicolumn{2}{|c|}{ Divorce } & $\begin{array}{l}\text { The family being dismantled ( } 6 \text { years after the } \\
\text { wedding), Debt, Legal action }\end{array}$ \\
\hline & \multicolumn{2}{|c|}{ Remarrying } & $\begin{array}{l}2 \text { years of adaptation period, Her role as the } \\
\text { eldest daughter-in-law of the family }\end{array}$ \\
\hline \multirow{3}{*}{$\begin{array}{l}\text { Problems } \\
\text { of the } \\
\text { children }\end{array}$} & \multicolumn{2}{|c|}{ Play environment } & $\begin{array}{c}\text { Lack of playthings, Lack of time to play with } \\
\text { parents }\end{array}$ \\
\hline & \multicolumn{2}{|c|}{ Underachieving } & Blurred pronunciation, lost desire \\
\hline & \multicolumn{2}{|c|}{ Early treatment } & $\begin{array}{l}\text { Beneficiary of the voucher, Acceptance of reality, } \\
\text { Teacher's recommendation, Spouse's support }\end{array}$ \\
\hline \multirow{8}{*}{$\begin{array}{l}\text { Psycholo- } \\
\text { gical and } \\
\text { emotional } \\
\text { problems }\end{array}$} & \multirow{4}{*}{$\begin{array}{l}\text { immigran } \\
t \text { women }\end{array}$} & Prejudice & Coming from abroad \\
\hline & & $\begin{array}{l}\text { Building } \\
\text { relationship }\end{array}$ & $\begin{array}{l}\text { Confining herself to home, Friends, Not having } \\
\text { relatives, Fear, Loneliness }\end{array}$ \\
\hline & & $\begin{array}{l}\text { Double } \\
\text { burdens }\end{array}$ & $\begin{array}{l}\text { Parenting, Education and employment, Special } \\
\text { education }\end{array}$ \\
\hline & & Shrinkage & $\begin{array}{l}\text { Absence of family(family in the home country, } \\
\text { brothers, sisters), Discrimination }\end{array}$ \\
\hline & \multirow{4}{*}{ Children } & $\begin{array}{l}\text { Discontinuation } \\
\text { of } \\
\text { Communication }\end{array}$ & Favoritism to younger brother(sister), Regression \\
\hline & & $\begin{array}{l}\text { Emotional } \\
\text { anxiety }\end{array}$ & $\begin{array}{c}\text { Stress due to dual cultures, Impulsive, Aggressive } \\
\text { behaviors }\end{array}$ \\
\hline & & Exclusion & $\begin{array}{c}\text { Adoption of the mother's surname, Delayed } \\
\text { learning }\end{array}$ \\
\hline & & $\begin{array}{l}\text { Shrinkage, } \\
\text { Depression }\end{array}$ & Parents' divorce, Home anxiety, Troubled heart \\
\hline
\end{tabular}

\section{Conclusion and Suggestion}

\subsection{Conclusion}

The main results revealed in the subject study are as follows. First, the difficulties which the married immigrant women revealed are those related to the spouses and the husbands' families. It was revealed that they suffered from the spouse's drinking problem and irresponsibility, or were disrespected or ignored from the spouse's family while facing the economical difficulty and psychological frustration. Second, the problems of parenting the 
children and education in the forms of the children's emotional maladaptation or being excluded from the age group, the pronouncing of the child as disabled, etc., made it more difficult to adapt to a new country. Third, both the parents and the children experienced prejudice and discrimination, and they need the familial support, and the social and emotional support as they were in the psychologically unstable status. When we see the procedures in which the married immigrant women adapt to the Korean society, they in the beginning experience the difficulty of being frustrated due to the crumbled expectation which they had before they came to Korea. Thereafter, they continue to suffer due to prejudice and discrimination against the multicultural families. Thereafter, they received the familial support and the social and emotional support as well as the parental counseling so that they regained their confidence and came to adapt to the Korean society through their independent effort to stand alone.

\subsection{Suggestion}

Even though the two married immigrant women interviewees who are Chinese Korean were fluent in Korean so as not to have problem in communication, it took 7-8 years for them to adapt to the Korean society and lead stable lives. Their adaption to the Korean society strongly reflects the aspect of their assimilation into the main society, and therefore, connoting many problems. And it is shown that the national support policies for the multicultural families should begin with the support for the early stage of their settlement.

Based on the problems exposed through the interviews, my suggestion for the multicultural policies as follows: First, education is necessary for not only the married immigrant woman but also for all the multicultural family members. The multicultural education often focuses on the married immigrant women or the children of the multicultural families. However, there are few programs for the Korean spouses and their family members who are the source of the discord or conflicts, and therefore, we need to develop various kinds of such programs. Social integration is possibile when the main streamers and the non-mainstreamers change together with both of their features still holding, and not when a certain part of the society is one-sidedly assimilated. Second, the usual people's narrow-minded views on the multicultural families should change. We should be aware that the problems of the multicultural families are not only theirs but also ours too. Third, it is urgent to intervene in the problems of education and maladaptation in the multicultural families, and we should understand that their difficulties cannot but be bigger than the usual Korean families and therefore, careful 
consideration and care is required. Fourth, the married immigrant woman's family being migrated to Korea can be one of the methods to help her overcome the psychological and emotional difficulties due to her being alone far away from her home country, which helps to lead a stable settlement.

[Table 2] Countermeasure resources in Adaptation to Korea

\begin{tabular}{|c|c|c|c|}
\hline \multirow{7}{*}{$\begin{array}{l}\text { Counter- } \\
\text { measure } \\
\text { resources }\end{array}$} & \multirow{3}{*}{$\begin{array}{l}\text { familial } \\
\text { support }\end{array}$} & $\begin{array}{l}\text { Support for the family } \\
\text { members in the home } \\
\text { country }\end{array}$ & $\begin{array}{l}\text { The married immigrant woman's parents, brothers, } \\
\text { sisters, etc. }\end{array}$ \\
\hline & & $\begin{array}{l}\text { Support for the } \\
\text { husband's family } \\
\text { members }\end{array}$ & The husband's sisters, parents, etc. \\
\hline & & Support for the spouse & Parenting of the children, Psychological support \\
\hline & \multirow{4}{*}{$\begin{array}{l}\text { social } \\
\text { support }\end{array}$} & Social association & Mutual communication with Korean neighbors \\
\hline & & Voucher & Language, Cognition, Psychological art therapy \\
\hline & & Multicultural Centers & No support for the Korean Chinese at all \\
\hline & & Parental counseling & $\begin{array}{l}\text { Time being short, Helpful for learning how to play the } \\
\text { role of a parent, Information for special education, } \\
\text { They wish the therapy to be opened }\end{array}$ \\
\hline
\end{tabular}

\section{References}

[1] Ministry of Health and Welfare, Statistics of social Welfare, Seoul (2016)

[2] E. J. Park, Intermarried Immigrant Women's Acculturation, Stress, and Psychological Health, Master's thesis, Graduate School in Chungnam National University (2007)

[3] G. Y. Kweon and K. W. Park, A Study on Influence Factors to the Mental Health of Foreign Wives, Korean Journal of Social Issues (2007), Vol.14, pp.187-219.

[4] M. K. Kim, Mental Health of Immigrant Women in Rural Communities -Focusing on Acculturative Stress and Social Support-, Korean Journal of Family Welfare (2007), Vol.12, No.3, pp.47-73.

[5] Statistics Office, Dynamic statistics of population (Matrimony • Divorce) (2016)

[6] D. H. Seol, Y. T. Kim, H. M. Kim, H. M. Yoon, H. S. Lee, H. K. Im, G. S. Han, A Study on Mental Health and Welfare Policy for Immigrant Women, Material from Ministry of Health and Welfare, Seoul 
(2005).

[7] http://biz.heraldcorp.com/commom_prog/Okt, Oct. 24 (2017)

[8] J. W. Berry, Multicultural policy in Canada: A social psychological analysis, Canadian Journal of Behavioral Science (1984), Vol.16, No.4, pp.353-370.

[9] C. L. Williams and J. W Berry, Primary prevention of Acculturative Stress among refugees: Application of Psychological Theory and Practice, American Psychologist (1991), Vol.46, No.6, pp.632-641.

[10] http://www.newspim.com/news/view/20170517000300, May 18 (2017), Newspim.

[11] G. S. Kim, A Study on the realities of child education in a multi-cultural family in Korea, Master's thesis, Seoul National University of Education (2006)

[12] J. Y. Kim, J. W. Kim \& S, O, Jeon, Parents education for young children, Changjisa, Seoul (2009) 